\title{
EVIDÊNCIAS DO EFEITO DA REPETÊNCIA NOS PRIMEIROS ANOS ESCOLARES
}

\author{
ERISSON VIANA CORREA \\ ALICIA BONAMINO \\ TUFI MACHADO SOARES
}

\section{RESUMO}

No contexto do debate sobre as vantagens e desvantagens da repetência escolar como medida pedagógica, este trabalho pretende verificar os efeitos dessa prática sobre o desempenho de estudantes dos anos iniciais do ensino fundamental. 0 objetivo é investigar se alunos que repetiram, mesmo ao custo de um ano extra de escolarização, apresentam ganhos reais de proficiência que justifiquem a utilização de tal medida. Para tanto, desenvolvemos um estudo observacional que compara dois grupos de alunos, repetentes e promovidos, organizados por pareamento assistido, analisando o impacto da repetência nas medidas de proficiência em Língua Portuguesa e Matemática desses grupos em diferentes momentos da sua trajetória escolar. Os resultados mostram que, ao longo do tempo, os alunos repetentes aprendem menos que os promovidos. Quando comparados em uma mesma série, independente do ano letivo em que a cursaram, os repetentes se saem methor, embora o efeito em Língua Portuguesa se perca ao longo das séries.

* O presente trabalho foi realizado com apoio do Programa Observatório

da Educação, da Coordenação de Aperfeiçoamento de Pessoal de Nivel Superior (Capes/Brasil) 


\title{
RESUMEN
}

En el marco del debate sobre las ventajas y desventajas de la repitencia escolar como medida pedagógica, este trabajo pretende verificar los efectos de tal práctica sobre el desempeño de estudiantes de los años iniciales de la educación fundamental. El objetivo es investigar si los alumnos que repitieron, inchuso con el costo de un año más de escolarización, presentan aumentos reales de proficiencia que justifiquen la utilización de tal medida. Para ello desarrollamos un estudio observacional que compara dos grupos de alumnos, repitentes y promovidos, organizados por pares asistidos, analizando el impacto de la repitencia en las medidas de proficiencia en Idioma Portugués y Matemática de dichos grupos en diferentes momentos de su trayectoria escolar. Los resultados muestran que, con el tiempo, los alumnos repitentes aprenden menos que los promovidos. Cuando comparados en un mismo curso, independientemente del año lectivo en que se encuentran, los repitentes obtienen mejores resultados, aunque el efecto en Idioma Portugués se pierda a lo largo de los distintos cursos.

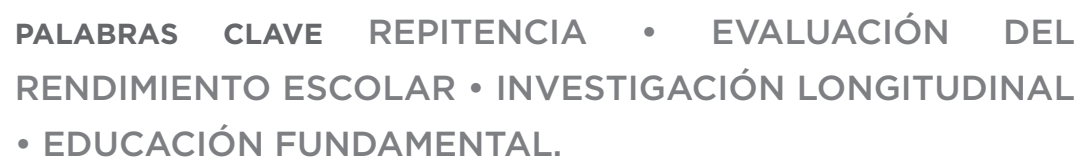

\begin{abstract}
In the context of the debate about the advantages and disadvantages of school retention as a pedagogic method, this study intends to verify the effects of this practice on the performance of students in the first years of schooling. The objective is to investigate whether students who repeat, even at the cost of an extra year of schooling, show real gains in proficiency that justify the use of such a measure. To accomplish this, we developed an observational study that compares groups of students, retained and promoted, organized by assisted pairing, analyzing the impact of retention on the proficiency measures on these groups in Portuguese language and Mathematics, at different moments along their school path. The results show that, over time, the retained students learn less than the promoted students. When compared within the same grade, independent of the school year of the student, the retainees were more successful, although the effect on the Portuguese language gets lost over the grades.

KEYWORDS RETENTION • ASSESSMENT OF SCHOOL PERFORMANCE • LONGITUDINAL RESEARCH • ELEMENTARY EDUCATION.
\end{abstract}




\section{INTRODUÇÃO}

Os altos níveis de repetência estão entre os mais graves e crônicos problemas educacionais do país. Sua existência está ligada à baixa qualidade do ensino, e as altas taxas de defasagem idade/série e de evasão escolar são suas consequências diretas. A extensão e a intensidade do uso desse recurso por parte das unidades escolares têm sido um fator de enorme pressão sobre os indicadores de fluxo e rendimento nos sistemas de ensino brasileiros.

As preocupações com a disseminação da repetência escolar no Brasil vêm de longa data. Nas décadas de 1930 e 1940 , com as primeiras tentativas de sistematizar os levantamentos estatísticos sobre a situação educacional do país, Teixeira de Freitas e Lourenço Filho protagonizaram intensos debates acerca do melhor tratamento e da interpretação dos dados estatísticos relativos ao ensino básico (TEIXEIRA DE FREITAS, 1937, 1941; LOURENÇO FILHO, 1941, 2002; GIL, 2007; GADOTTI; ROMÃO, 2000). Decisões equivocadas tomadas àquela época incorporaram aos dados oficiais erros graves que distorceriam as estatísticas, superestimando as taxas 
de evasão e subestimando as de repetência. Como resultado, inúmeras análises baseadas nesses dados chegaram a diagnósticos equivocados e imprecisos sobre esse problema educacional. A política educacional decorrente privilegiou por muito tempo a expansão quantitativa do atendimento escolar em detrimento da melhoria da qualidade.

Zaia Brandão, Anna Maria Baeta e Any Dutra Rocha (1983), em clássico estudo sobre o estado do conhecimento acerca da evasão e da repetência, verificaram que as investigações evidenciavam um estrangulamento na base do sistema escolar, concentrado na passagem da primeira para a segunda série, além da inadequação do tratamento pedagógico dado à questão da repetência.

Concomitantemente, um grupo de pesquisadores apontou as falhas das estatísticas oficiais em uma série de estudos desenvolvidos desde a década de 1980 e considerados fundamentais para a compreensão do problema da repetência no Brasil (FLETCHER, 1985; FLETCHER; CASTRO, 1986; FLETCHER; RIBEIRO, 1987; RIBEIRO, 1991; KLEIN; RIBEIRO, 1991).

Com base em um modelo denominado Profluxo, que utilizava dados coletados na Pesquisa Nacional de Amostra por Domicílio (Pnad) do Instituto Brasileiro de Geografia e Estatística (IBGE), constatou-se que as altíssimas taxas de repetência na primeira série do então ensino de primeiro grau interrompiam de tal forma o fluxo, que produziam, já ao final do primeiro ano de escolaridade, um gargalo que bloqueava a entrada de novas coortes de alunos no sistema escolar. Essa retenção elevava substancialmente a distorção idade/série e depreciava o rendimento dos alunos, em um processo acumulado que se arrastava desde a entrada até a saída daquela coorte do sistema, configurando, assim, talvez o nosso maior problema educacional.

Diversas medidas de correção de fluxo foram adotadas com maior ênfase a partir desses achados. A repetência, que estava em um patamar de $60 \%$ nos anos 1980 , caiu para próximo de $45 \%$ na década de 1990 e recuou mais um pouco nos anos 2000, estabilizando-se em um patamar ainda alto, em torno dos $25 \%$ (KLEIN, 2006).

Grande parte da queda observada na primeira série se deve à introdução das Classes de Alfabetização em alguns 
1 Subseriação refere-se à prática de repartir a primeira série em duas etapas de escolarização. Essa estratégia era corrente até instituição do ensino fundamental de nove anos.
2 Em recente relatório do Pis (ORGANIZAČÃO PARA A COOPERAÇÃO E DESENVOLVIMENTO ECONÔMICO, 2011), o Brasil aparece situado entre os três países que apresentam a maior quantidade de alunos com experiência prévia de repetência, atrás apenas de Tunísia e Macau estados, com a instituição de uma política muito comum na época: a "subseriação". ${ }^{1}$ Além disso, a introdução do Ciclo Básico de Alfabetização (CBA) acabou com a possibilidade de reprovação na $1^{a}$ série, diminuindo as taxas de repetência (KLEIN; RIBEIRO, 1998). A queda significativa nas taxas de repetência, ao longo das décadas de 1980 e 1990, principalmente na primeira série, também foi reflexo direto da adoção de medidas como as Classes de Aceleração, a organização escolar em Ciclos e a Promoção Automática. No entanto, a despeito da importante melhoria nas taxas de fluxo alcançada pelo Brasil na década de 1990, ainda estamos entre os países com as maiores taxas de repetência no mundo, perdendo apenas para Angola (SOARES, 2007). ${ }^{2}$

\section{LITERATURA SOBRE A REPETÊNCIA}

A literatura sobre repetência e as políticas educacionais vigentes no Brasil, a partir da década de 1990, sofreram influência significativa das descobertas da década anterior, motivadas pelas conclusões do modelo Profluxo.

O artigo "A pedagogia da repetência" (RIBEIRO, 1991) é representativo do momento histórico de mudança na perspectiva das análises sobre o problema da repetência. Sérgio da Costa Ribeiro colocou em xeque os dados estatísticos fornecidos pelo Ministério da Educação (MEC), mostrando que o maior entrave para o aumento da escolaridade da população brasileira era a repetência e não as altas taxas de evasão.

Durante esse período, o debate sobre os problemas decorrentes da repetência escolar no Brasil esteve circunscrito à mensuração e análise do fluxo escolar e à compreensão dos aspectos sociais e culturais envolvidos nesse fenômeno.

Mais recentemente, outros estudos buscaram compreender os efeitos de políticas de não retenção. Naércio Menezes-Filho et al. (2008) avaliaram o impacto da implantação de programas de progressão continuada nos indicadores de rendimento das escolas e no desempenho dos alunos, com base nos dados do Censo Escolar 2006 e da Prova Brasil 2005. Os estudos identificaram o aumento da aprovação acompanhado da diminuição do abandono escolar em todas as séries, entretanto, com perda significativa para o desempenho dos alunos 
da $8^{\text {a }}$ série. Carvalho (2009) avaliou o impacto das políticas de não retenção no desempenho acadêmico de alunos do ensino fundamental de escolas públicas brasileiras. Utilizando dados do Censo Escolar 2001 e 2005, e resultados do Saeb 2001 e da Prova Brasil 2005, o autor constatou que a prática de não retenção não teve impacto algum sobre o desempenho dos alunos, nem mesmo entre aqueles com pior desempenho, grupo que se julgava ser beneficiado por essa ação.

Neves e Pazello (2012) investigaram o impacto das mudanças nas políticas de promoção das escolas a partir de resultados do Saeb, no período 1999-2003. Os achados dessa pesquisa mostram que as escolas que aboliram a repetência tiveram um acréscimo no desempenho em Matemática, mas não em Língua Portuguesa, entre os alunos da $4^{\mathrm{a}}$ série quando comparados às escolas que seguiram com o regime seriado. Não foram encontrados, no entanto, efeitos significativos para a $8^{\mathrm{a}}$ série em nenhuma das duas disciplinas. Entre as escolas que abandonaram os sistemas de progressão e passaram a utilizar o regime de repetência, a pesquisa indicou um resultado superior em Matemática na $4^{\mathrm{a}}$ série apenas para a regressão realizada no âmbito do aluno. Na $8^{\mathrm{a}}$ série, os alunos apresentaram um desempenho inferior em Matemática, tanto no âmbito do aluno quanto no âmbito da escola, e desempenho inferior em Língua Portuguesa, significativo apenas para o âmbito da escola.

Mais recentemente, com a emergência dos dados longitudinais, já começam a despontar no Brasil trabalhos sobre o efeito da repetência propriamente dita, e não apenas das políticas antirrepetência. Embora incipiente no Brasil, esse tipo de estudo tem uma longa tradição no debate internacional.

Parte importante desse debate foi introduzida no Brasil por Marcel Crahay (2006) em um artigo que revisa uma série de estudos sobre o efeito da repetência. Nele, o autor sintetiza quase um século do percurso da pesquisa sobre o tema e suas principais evoluções metodológicas. Para o autor, a trajetória recente dessas pesquisas pode ser considerada paradigmática, pelas múltiplas tentativas de aproximação da análise científica à realidade da prática escolar, motivada pelos esforços de diversos pesquisadores que, ao longo desse período, 
procuraram tanto contornar obstáculos metodológicos como responder às objeções lançadas a esse tipo de pesquisa. $\mathrm{O}$ estudo conclui que o fato de repetir uma série e recomeçar todo o programa de curso não ajuda alunos com dificuldades a superarem os obstáculos e obterem sucesso escolar.

Luciana Soares Luz (2008) é autora de um dos primeiros estudos no contexto brasileiro a utilizar dados longitudinais para analisar os efeitos da repetência. Fazendo uso dos resultados da base Fatores Associados ao Desempenho Escolar - Centro de Desenvolvimento de Planejamento Regional da Universidade Federal de Minas Gerais (Cedeplar)/Instituto Nacional de Estudos e Pesquisas Educacionais Anísio Teixeira (Inep), a autora realizou um pareamento entre alunos repetentes e promovidos da $7^{\mathrm{a}}$ série, em 2002, a partir do método de escores de propensão. Na comparação dos escores desses alunos entre a $7^{\mathrm{a}}$ série em 2002 e a $8^{\mathrm{a}}$ série em 2008, os resultados obtidos mostram que os alunos repetentes obtêm ganhos na proficiência inferiores aos dos alunos nas mesmas condições e que foram promovidos. Ao final do ano repetido, o desempenho dos repetentes é muito parecido com o de seus novos colegas de turma e bastante inferior ao apresentado pelos alunos que progrediram.

Mais recentemente, Juliana Riani, Vania Silva e Tufi Soares (2010) conduziram novo estudo sobre efeitos da repetência no contexto brasileiro, a partir dos dados do Proalfa - Avaliação da Alfabetização da Rede Pública do Estado de Minas Gerais - com o objetivo de compreender se a retenção dos alunos que cursavam o $3^{\circ}$ ano de escolaridade em 2009 foi ou não benéfica em termos de aprendizado. Os autores utilizaram modelos hierárquicos e, por meio deles, mostraram que dado dois alunos com uma mesma proficiência em 2008, um deles sendo promovido e o outro retido no $3^{\circ}$ ano, o promovido tende a apresentar maior proficiência em 2009. Os resultados obtidos indicam, também, que o resultado geral da escola tem grande influência sobre os alunos de baixo desempenho, o que leva à consideração de que expor alunos repetentes ao mesmo conteúdo, com base no pressuposto de que existiria uma deficiência de aprendizagem decorrente unicamente da sua inabilidade para apreender, não resolverá 
o problema, uma vez que fatores intraescolares possuem impacto significativo sobre a aprendizagem dos alunos.

\section{METODOLOGIA}

Antes dos primeiros esforços de estudos baseados em metodologias quase experimentais, diversos pesquisadores já se ocupavam em avaliar os efeitos da repetência em uma perspectiva comparada por meio da observação dos alunos retidos e promovidos. Entretanto, essas investigações tendiam a favorecer os alunos promovidos, uma vez que não se preocupavam em isolar as características individuais e familiares que poderiam interferir na formação e na comparação dos grupos de alunos retidos e não retidos (JACKSON, 1975).

As primeiras investigações que se preocuparam em captar os efeitos da repetência no desempenho dos alunos se baseavam em desenhos bastante elementares, denominados esquemas pré e pós-teste. Essas pesquisas selecionavam amostras formadas exclusivamente por alunos com dificuldade escolar. Seus conhecimentos eram testados a partir de exames, em que o primeiro teste era aplicado antes da decisão da repetência e o outro depois. Para garantir igualdade nas medidas, os pesquisadores utilizavam os mesmos testes cognitivos e isso impunha uma forte limitação ao estudo (JACKSON, 1975). Todos os estudos que se utilizaram desse delineamento naturalmente concluíram a favor de uma clara evolução cognitiva dos alunos repetentes.

Constatada essa limitação metodológica, os pesquisadores procuraram alternativas que permitissem mensurar os efeitos da repetência de uma forma mais apurada. A pesquisa experimental foi o modelo adotado para a compreensão dos efeitos da repetência, o que exigiria dos pesquisadores das ciências sociais e humanas posturas pouco convencionais diante de impedimentos de diversas ordens. Em primeiro lugar, o rigor exigido pela pesquisa experimental demandava que se procedesse a uma escolha aleatória dos indivíduos que comporiam os grupos. Depois, para garantir que não se introduzisse nenhum viés na comparação, seria necessário que os grupos formados apresentassem certa equivalência 
4 Assim denominados em referência à obra de Thomas Cook e Donald Campbell (1979). inicial que permitisse a comparabilidade entre eles. Por último, um estudo para ser considerado experimental de fato exigiria que o pesquisador tivesse pleno domínio sobre o tratamento a ser administrado.

As dificuldades encontradas para se estabelecer com segurança dois grupos distintos de alunos em que cada indivíduo de um grupo tenha as mesmas características socioeconômicas e de aprendizagem de um indivíduo do outro grupo, aliadas às restrições de escolha dos alunos por meio de sorteio, no qual todos tenham as mesmas probabilidades de receber o tratamento, colocaram os pesquisadores diante de um problema ético. A primeira proposta no sentido de superar essas dificuldades foram os estudos quase experimentais ou passive observacional studies (estudos observacionais), ${ }^{4}$ assim denominados em referência à obra de Cook e Campbell (1979). Esses estudos buscaram acompanhar, durante determinado intervalo de anos, a evolução cognitiva de um conjunto de alunos com capacidades cognitivas iniciais semelhantes, sendo uns submetidos à retenção na mesma série e outros promovidos à série seguinte.

Nesta pesquisa aproveitaremos o potencial empírico desse tipo de delineamento aliado à possibilidade de exploração dos dados da Pesquisa Geres (Estudo Longitudinal da Geração Escolar). Com isso, pretendemos oferecer uma contribuição ao debate sobre as vantagens e desvantagens da repetência no Brasil.

\section{DELINEAMENTO DA PESQUISA}

Este estudo pretende responder a duas questões básicas: 1) Os alunos que passam pela experiência da repetência apresentam ganhos reais de proficiência que justifiquem a utilização de tal medida mesmo ao custo de um ano extra de escolarização? 2) No caso de haver ganhos reais na aprendizagem do aluno repetente, esses ganhos se mantêm ao longo dos anos iniciais do ensino fundamental?

Para responder a elas, comparam-se dois grupos de alunos, um formado por repetentes e outro por promovidos. Chamaremos o primeiro grupo, formado por alunos repetentes na $1^{\mathrm{a}}$ série $/ 2^{\circ}$ ano do ensino fundamental, de "grupo 
experimental" ou "grupo de tratamento". O segundo grupo, formado por alunos que não sofreram repetência, será denominado "grupo controle". O comportamento dos alunos do grupo controle representará o comportamento do grupo experimental caso os alunos não tivessem sido submetidos à repetência. As análises comparativas foram realizadas tanto para Língua Portuguesa quanto para Matemática.

Os dados utilizados nesta investigação fazem parte da base de dados global da Pesquisa Geres 2005 (BROOKE; BONAMINO, 2011). Realizado entre 2005 e 2008, este estudo objetivou investigar a evolução das aprendizagens em Língua Portuguesa e Matemática de cerca de 21.500 alunos dos anos iniciais do ensino fundamental, matriculados em mais de 300 escolas de cinco cidades brasileiras: Belo Horizonte, Campinas, Campo Grande, Rio de Janeiro e Salvador. A pesquisa foi realizada em regime de colaboração interinstitucional entre seis universidades. ${ }^{5}$

O desenho do Geres foi construído a partir de uma amostra estratificada, com a participação de aproximadamente 300 escolas de diversas dependências administrativas: federais, estaduais, municipais e privadas. Durante os quatro anos do projeto, foram aplicadas cinco ondas de avaliação, duas no primeiro ano, em março e novembro de 2005, e as demais ao final de cada ano, até 2008. Além dos testes de proficiência em Língua Portuguesa e Matemática, foram aplicados também questionários contextuais sobre a escola, os professores, os diretores, os pais e os próprios alunos, com o objetivo de coletar dados que revelassem aspectos escolares, sociais e familiares que pudessem influenciar no desempenho destes últimos.

A construção dos testes cognitivos contou com a participação de especialistas da Pontifícia Universidade Católica do Rio de Janeiro (PUC-Rio) e do Centro de Alfabetização, Leitura e Escrita da Universidade Federal de Minas Gerais (Ceale/UFMG) para a elaboração da matriz de referência e dos testes de Língua Portuguesa, e da Universidade Federal de Juiz de Fora (UFJF) para a matriz de referência e dos testes de Matemática, bem como para a elaboração das escalas de proficiência da pesquisa. 
As proficiências do Geres foram estimadas por meio do modelo proposto pela Teoria da Resposta ao Item (TRI) e sua escala foi equalizada com a do Saeb. Suas vantagens incluem uma melhor comparabilidade dos resultados alcançados pelos alunos nos testes construídos a partir de um conjunto de diferentes itens e aplicados em diferentes momentos (BROOKE; BONAMINO, 2011). Isso permite que esses alunos possam ter suas proficiências avaliadas de acordo com uma mesma escala, apesar de terem respondido testes diferentes. Os questionários contextuais, por sua vez, foram elaborados no sentido de permitir aos pesquisadores testar hipóteses relativas às características escolares, familiares, sociais, dos professores, gestores e alunos que poderiam influenciar nos resultados escolares. Além disso, há outros blocos de itens que foram construídos com base no interesse de testar a existência de certos construtos teóricos, como a motivação do aluno, por exemplo.

A principal vantagem do Geres é ser longitudinal, oferecendo dados cognitivos comparáveis durante os quatro anos iniciais do ensino fundamental. Isso permite um desenho de estudo observacional capaz de captar possíveis efeitos pedagógicos da repetência ao longo do tempo.

As observações correspondem às ondas de avaliação do estudo longitudinal. Isso quer dizer que nossa primeira observação será realizada com os alunos antes da decisão da repetência e as observações seguintes após a repetência. A Figura 1 apresenta a configuração da pesquisa, a partir do delineamento adotado. 
FIGURA 1 - Esquema conceitual da pesquisa sobre o efeito da repetência

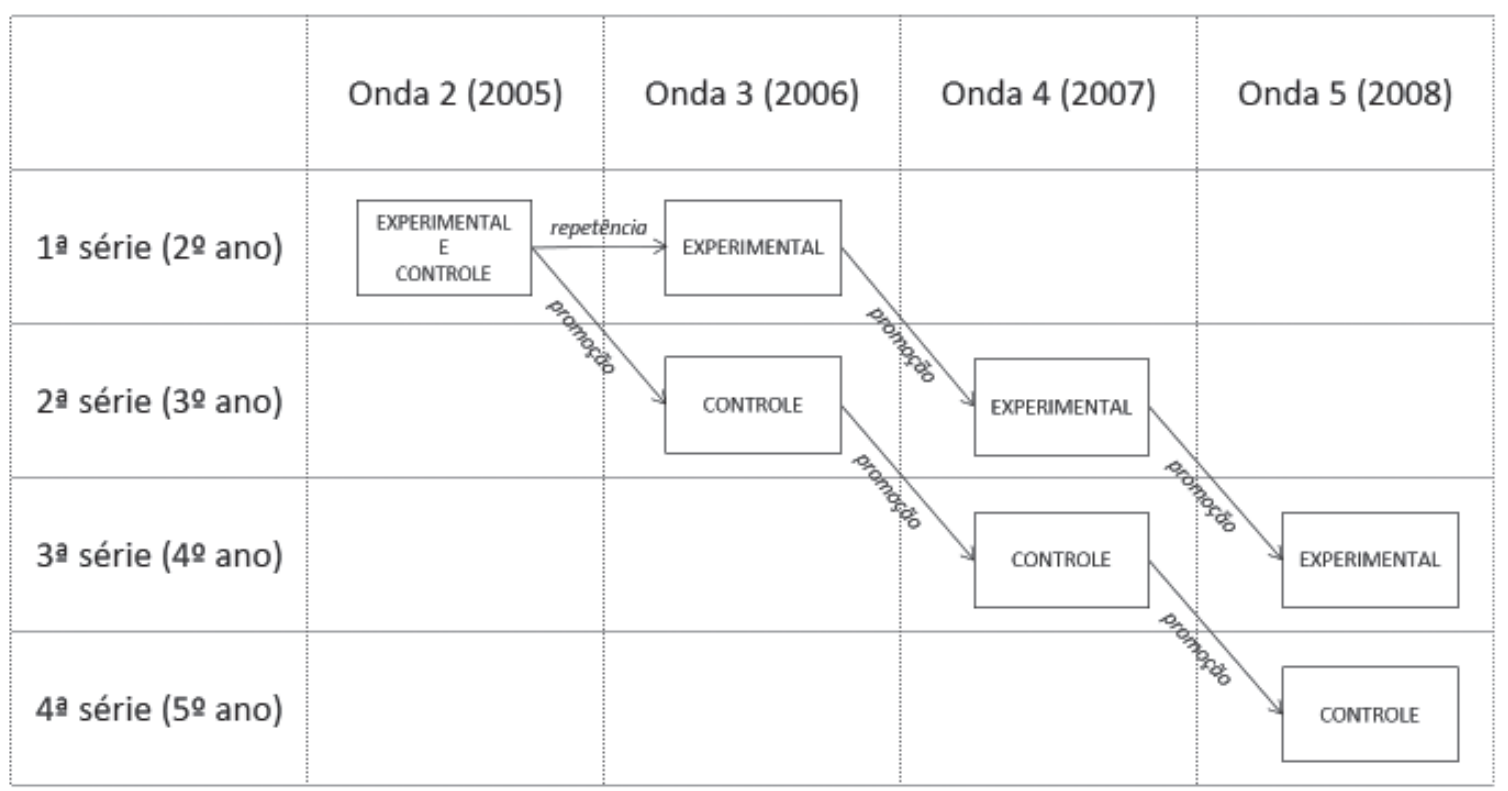

Fonte: Elaboração dos autores.

Na Figura 1, estão representadas, num esquema de fluxo, as trajetórias escolares dos dois grupos a serem pesquisados. No eixo horizontal, verificam-se os anos de aplicação do estudo longitudinal, divididos em quatro avaliações, que vão de 2005 a 2008. No eixo vertical, observam-se as séries cursadas pelos mesmos grupos de alunos. À medida que os grupos avançam nas colunas, há uma mudança no ano calendário, da mesma forma, quando mudam de linha, representa um avanço na série cursada.

Esse delineamento permite abordagens de dois tipos. No plano vertical, de acordo com a evolução das proficiências dos alunos no decorrer dos anos, que chamaremos "comparação por ondas”. No plano horizontal, a partir das séries cursadas, o que denominaremos "comparação por série". A partir desse desenho pretendemos compreender se a repetência, a despeito de um ano a mais de escolaridade, leva os alunos do grupo experimental a apresentar maiores ganhos de proficiência do que os alunos do grupo controle que tiveram o mesmo ponto de partida.

Para a seleção dos indivíduos que comporão os grupos recorreremos a uma técnica denominada pareamento assistido ${ }^{6}$ (ou matching). Essa técnica consiste em escolher para cada

6 O pareamento assistido consiste em tentar encontrar visualmente registros iguais na base de dados para os grupos de tratamento e controle. Ele permite alcançar o melhor pareamento possível desde que não haja muitos casos sendo tratados, nem muitas variáveis de controle. É particularmente indicado no caso de haver muitas opções para compor o grupo de controle, o que ocorre no presente estudo. 
aluno do grupo experimental, outro indivíduo que não recebeu o tratamento e tem características idênticas a ele. $\mathrm{O}$ processo é descrito em detalhes na próxima seção.

\section{O PROCESSO DE PAREAMENTO}

Para proceder ao pareamento escolheram-se, como variáveis de controle, a proficiência em Língua Portuguesa e a proficiência em Matemática da $2^{\mathrm{a}}$ Onda de avaliação do estudo longitudinal, o Indicador de Nível Socioeconômico (NSE), a dependência administrativa e o município, tendo como objetivo controlar possíveis distorções na comparação entre alunos provenientes de diferentes configurações sociais, redes ou tipos de escolas.

As unidades não pareadas, ou seja, aquelas que não se encaixam nos perfis definidos para esta pesquisa por não estarem de acordo com os critérios estabelecidos foram descartadas e, portanto, não farão parte dos resultados. Foram excluídos, também, os alunos que sofreram repetências a posteriori, pois o período de escolaridade visado pelo estudo longitudinal (os quatro anos iniciais do ensino fundamental) impõe uma limitação temporal que não permite a análise da trajetória de alunos retidos mais de uma vez.

Dentre os 19.757 alunos que iniciaram o estudo longitudinal, foram identificados 297 casos elegíveis para o grupo experimental, o que equivale aos alunos que estariam cursando pela segunda vez a $1^{\mathrm{a}}$ série $/ 2^{\circ}$ ano do ensino fundamental, no momento da aplicação da Onda 3 , e que não sofreram mais nenhuma repetência até o fim do estudo longitudinal.

Identificaram-se 9.558 casos de alunos elegíveis para o grupo controle, abrangendo os alunos com trajetórias escolares regulares, sem repetência, e com participação do estudo longitudinal em todos os anos. Esses alunos estavam cursando a $1^{\mathrm{a}}$ série $/ 2^{\mathrm{a}}$ ano quando se aplicou a Onda 2 , cursavam a $2^{\mathrm{a}}$ série $/ 3^{\circ}$ ano quando se aplicou a $3^{\mathrm{a}}$ Onda de avaliação e assim por diante.

O número total de repetentes segundo os critérios escolhidos foi de 297. Com o procedimento realizado conseguimos parear com grande aproximação 229 casos em 
Matemática e 243 em Língua Portuguesa. Dado o número de variáveis utilizadas (rede, estrato, proficiência e NSE) e a grande restrição que impusemos ao pareamento, ao admitirmos um distanciamento muito pequeno entre os casos controle e experimental, concluímos que o processo de matching foi bem-sucedido, com uma taxa de aproveitamento próxima a $80 \%$ para Matemática e Língua Portuguesa. Com isso, a distribuição de casos pelas redes ficou mais equânime, como pode ser observado no Quadro 1, a seguir.

QUADRO 1 - Distribuição do número de pares por rede e município Língua Portuguesa e Matemática

\begin{tabular}{|c|c|c|c|c|c|c|}
\hline & \multirow{2}{*}{ MUNICÍPIO } & \multicolumn{4}{|c|}{ REDE } & \multirow{2}{*}{ TOTAL } \\
\hline & & ESPECIAL $^{7}$ & ESTADUAL & MUNICIPAL & PRIVADA & \\
\hline \multirow{5}{*}{ 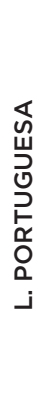 } & $\begin{array}{l}\text { Belo } \\
\text { Horizonte }\end{array}$ & 0 & 21 & 4 & 0 & 25 \\
\hline & Campinas $^{9}$ & 0 & 3 & 43 & 3 & 49 \\
\hline & $\begin{array}{l}\text { Campo } \\
\text { Grande }\end{array}$ & 0 & 38 & 98 & 0 & 136 \\
\hline & $\begin{array}{l}\text { Rio de } \\
\text { Janeiro }\end{array}$ & 19 & 0 & 7 & 7 & 33 \\
\hline & Total & 19 & 62 & 152 & 10 & 243 \\
\hline \multirow{5}{*}{ 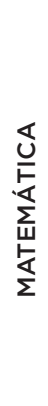 } & $\begin{array}{l}\text { Belo } \\
\text { Horizonte }\end{array}$ & 0 & 20 & 3 & 0 & 23 \\
\hline & Campinas & 0 & 2 & 38 & 3 & 43 \\
\hline & $\begin{array}{l}\text { Campo } \\
\text { Grande }\end{array}$ & O & 37 & 94 & 0 & 131 \\
\hline & $\begin{array}{l}\text { Rio de } \\
\text { Janeiro }\end{array}$ & 19 & 0 & 6 & 7 & 32 \\
\hline & Total & 19 & 59 & 141 & 10 & 229 \\
\hline
\end{tabular}

Fonte: Elaboração dos autores.

As distribuições dos repetentes e promovidos são idênticas e, como se pode ver no Quadro 2, bastante parecidas também entre as amostras de Matemática e Língua Portuguesa para outras variáveis de contexto. Para os valores de nível socioeconômico utilizamos como critério que alunos pareados,

$7 \mathrm{Na}$ coluna Rede, o estrato Especial abrange os Colégios de Aplicação vinculados a Universidades nas cidades do Rio de Janeiro e Belo Horizonte, bem como as escolas federais de educação básica no município do Rio de Janeiro.

8 Em Belo Horizonte, a rede municipal oferecia ensino fundamental de nove anos, organizado em três ciclos com duração de três anos cada. A rede estadual também oferecia ensino fundamental de nove anos com regime de ciclos, porém com configuração diferente. $\bigcirc$ primeiro ciclo tinha duração de três anos, atendendo crianças a partir de 6 anos de idade. Os ciclos seguintes tinham duração de dois anos cada.

9 Em Campinas, as redes municipal e estadual ofereciam ensino

fundamental com duração de oito anos, porém ambas com Classes de Alfabetização (CA) na pré-escola. A rede municipal se organizava em regime seriado, enquanto a rede estadual mantinha dois ciclos formados por quatro anos de escolaridade cada um.

10 Em Campo Grande, a rede municipal oferecia ensino fundamenta de nove anos, com os dois primeiros anos de escolaridade compondo um único ciclo e atendendo crianças de 6 e 7 anos de idade. Os demais anos de escolaridade seguiam em regime seriado. A rede estadual também oferecia ensino fundamental de nove anos, porém em regime seriado.

11 A rede municipal do Rio de Janeiro oferecia ensino fundamental de nove anos, cujos três primeiros anos compunham um ciclo (atendendo crianças de 6, 7 e 8 anos de idade) seguido do regime de seriação. 
seja no grupo experimental ou controle, guardassem entre si a distância de no máximo 0,6 pontos na escala de NSE. A diferença dos alunos repetentes com relação aos alunos promovidos foi de $-0,05$ pontos para o pareamento em Língua Portuguesa e de 0,04 pontos para o pareamento em Matemática.

Isso permitiu amostras mais homogêneas não só do ponto de vista da rede e da cidade, como também das características dos alunos, como podemos observar no Quadro 2, a seguir.

QUADRO 2 - Distribuição percentual dos grupos pareados quanto à cor/raça, sexo e frequência à pré-escola

\begin{tabular}{|c|c|c|c|c|c|}
\hline \multirow{2}{*}{\multicolumn{2}{|c|}{ CARACTERÍSTICAS }} & \multicolumn{2}{|c|}{ L. PORTUGUESA } & \multicolumn{2}{|c|}{ MATEMÁTICA } \\
\hline & & REPETENTES & PROMOVIDOS & REPETENTES & PROMOVIDOS \\
\hline \multirow{6}{*}{ Cor / raça } & Branco & 35,0 & 29,6 & 32,8 & 29,3 \\
\hline & Pardo & 30,9 & 46,1 & 31,4 & 45,0 \\
\hline & Preto & 17,3 & 14,8 & 17,5 & 14,0 \\
\hline & Amarelo & 2,1 & 2,9 & 3,1 & 3,5 \\
\hline & Indígena & 5,3 & 4,1 & 5,2 & 6,1 \\
\hline & $N / I$ & 9,5 & 2,5 & 10,0 & 2,2 \\
\hline \multirow{3}{*}{ Sexo } & Feminino & 35,8 & 40,3 & 35,8 & 47,2 \\
\hline & Masculino & 57,6 & 57,6 & 57,2 & 51,1 \\
\hline & $N / I$ & 6,6 & 2,1 & 7,0 & 1,7 \\
\hline \multirow{3}{*}{$\begin{array}{l}\text { Frequência à } \\
\text { Pré-escola }\end{array}$} & Não & 23,0 & 19,3 & 24,5 & 20,5 \\
\hline & Sim & 58,0 & 69,1 & 55,5 & 65,5 \\
\hline & $N / I$ & 18,9 & 11,5 & 20,1 & 14,0 \\
\hline
\end{tabular}

Fonte: Elaboração dos autores.

Como se pode observar, o número de meninos é maior tanto entre os repetentes quanto entre os promovidos, seja em Língua Portuguesa ou em Matemática. E as meninas estão mais presentes entre os promovidos. No que diz respeito à cor declarada, as distribuições são bem parecidas. Há um número maior de alunos pardos entre os promovidos para ambas as disciplinas. No que se refere à frequência à pré-escola, o número de alunos promovidos que frequentaram a educação infantil é cerca de 10 pontos percentuais maior que o dos alunos repetentes, tanto para o pareamento em Língua Portuguesa quanto em Matemática. 
No que diz respeito à medida de desempenho, em Língua Portuguesa a proficiência média ficou em torno de 106 pontos. Em Matemática, a média é de 112 pontos. As variações no tempo e nas séries observadas para as proficiências serão analisadas na próxima seção.

\section{RESULTADOS \\ O EFEITO DA REPETÊNCIA SOBRE A PROFICIÊNCIA}

Tradicionalmente, os autores que têm se voltado para a compreensão do efeito da repetência sobre o desenvolvimento cognitivo dos alunos se utilizam de duas abordagens básicas para a análise dos resultados (HOLMES, 1989). A primeira é uma estratégia de comparação denominada same-age comparison, pela qual os autores comparam os resultados de alunos repetentes com seus pares promovidos, levando em conta apenas a idade do aluno ou o ano em que a avaliação foi realizada, e ignorando a série cursada. A segunda estratégia adotada, denominada same-grade comparison, consiste em comparar o desempenho obtido pelos alunos repetentes em uma determinada série com o resultado obtido pelo aluno promovido para aquela mesma série no ano anterior. Adotaremos essas duas abordagens na pesquisa, adaptando-as ao estudo longitudinal.

\section{COMPARAÇÃO POR ANO OU ONDA (SAME-AGE COMPARISON}

Por meio desta primeira abordagem buscamos comparar as proficiências dos alunos em um mesmo ano letivo ou em uma mesma onda de avaliação, independente da série que tenham cursado naquele ano, como pode ser observado na Figura 2. 
FIGURA 2 - Estratégia de comparação por ano ou por onda de avaliação

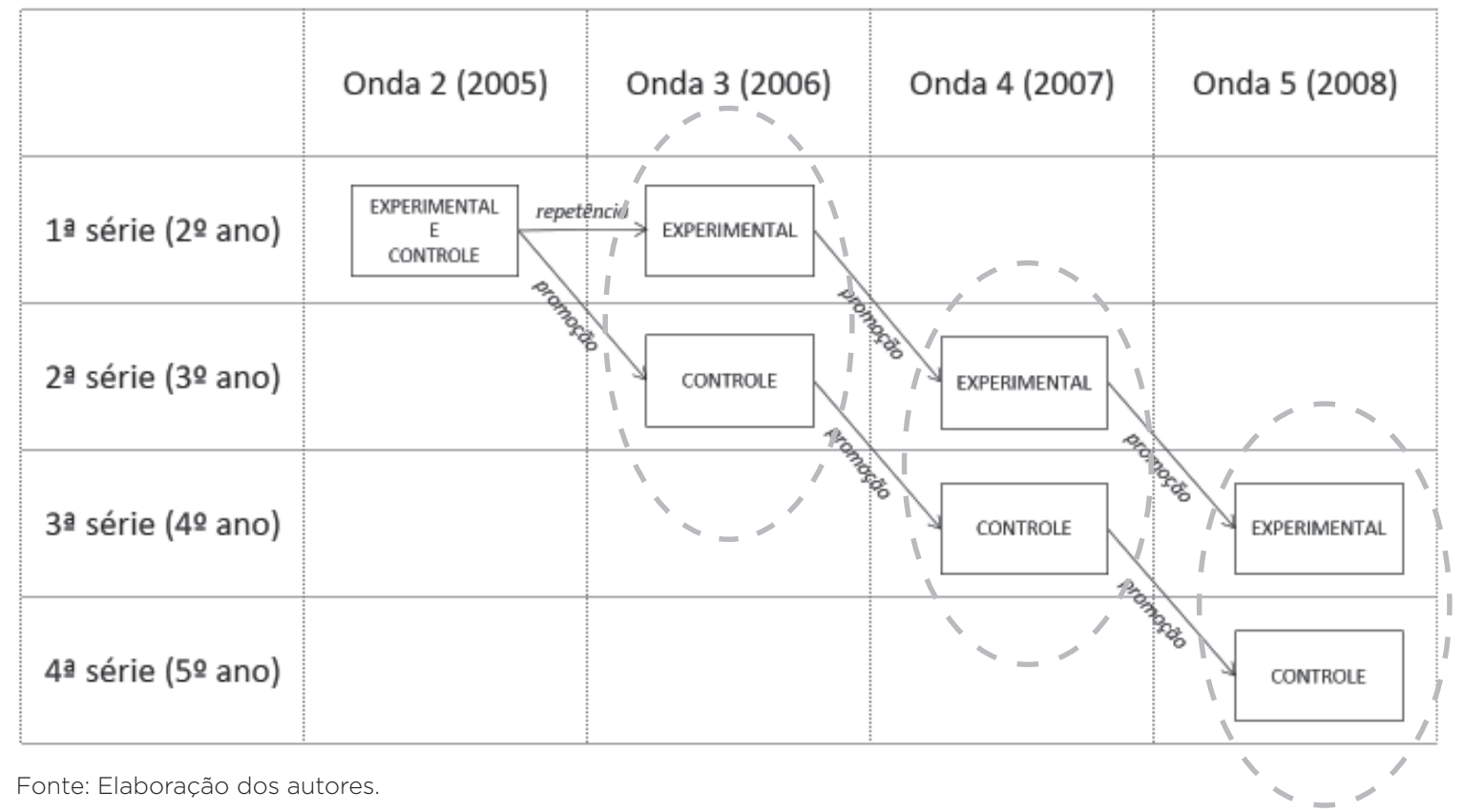

Incluímos no esquema de delineamento três círculos tracejados que indicam três comparações possíveis por meio dessa abordagem.

Os gráficos 1 e 2, a seguir, comparam as médias de proficiência em Língua Portuguesa e Matemática dos alunos repetentes e promovidos no decorrer das cinco ondas de avaliação. É importante relembrar que esses alunos foram submetidos ao pareamento a partir da $2^{\mathrm{a}}$ Onda, o que ocorreu no final de 2005, quando todos os alunos ainda cursavam a $1^{\text {a }}$ série $/ 2^{\circ}$ ano e nenhum deles ainda havia passado pela experiência da repetência. 


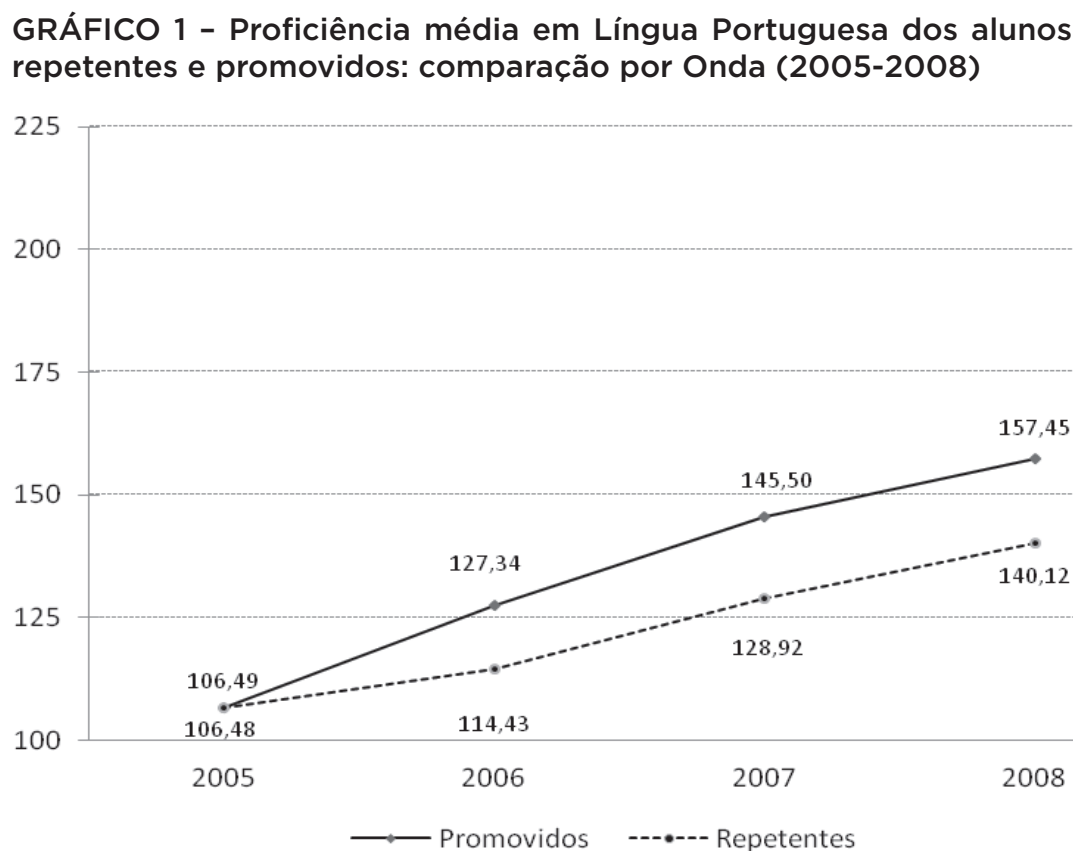

Fonte: Elaboração dos autores.

Como se pode ver na comparação por ano, as médias dos alunos repetentes e promovidos ao final de 2005 estão em patamares idênticos, próximos dos 106 pontos na escala de proficiência em Língua Portuguesa. A partir daí, ambos os grupos continuam progredindo, embora apenas os promovidos o façam em um ritmo constante, com crescimento médio em torno de 17 pontos ao ano, entre 2005 e 2007. No grupo de alunos repetentes, em 2006, quando estes cursaram pela segunda vez a $1^{\mathrm{a}}$ série $/ 2^{\circ}$ ano, há um crescimento médio de apenas 8 pontos, menos que a metade do crescimento atingido pelos alunos promovidos. A explicação para esse resultado pode estar no fato de os alunos promovidos terem sido expostos a conteúdos novos, constantes do programa da $2^{\mathrm{a}}$ série $/ 3^{\circ}$ ano, enquanto os alunos repetentes estariam revendo conteúdos da $1^{\mathrm{a}}$ série $/ 2^{\circ}$ ano. A retomada do ritmo do crescimento entre 2006 e 2007 em 14 pontos na escala de proficiência corrobora com esta possibilidade: apenas 4 pontos a menos que os alunos promovidos no mesmo período e 6 pontos a menos que no período anterior. Entre 2007 e 2008 , os dois grupos praticamente empatam no crescimento médio, acrescentando aproximadamente 11 pontos. 


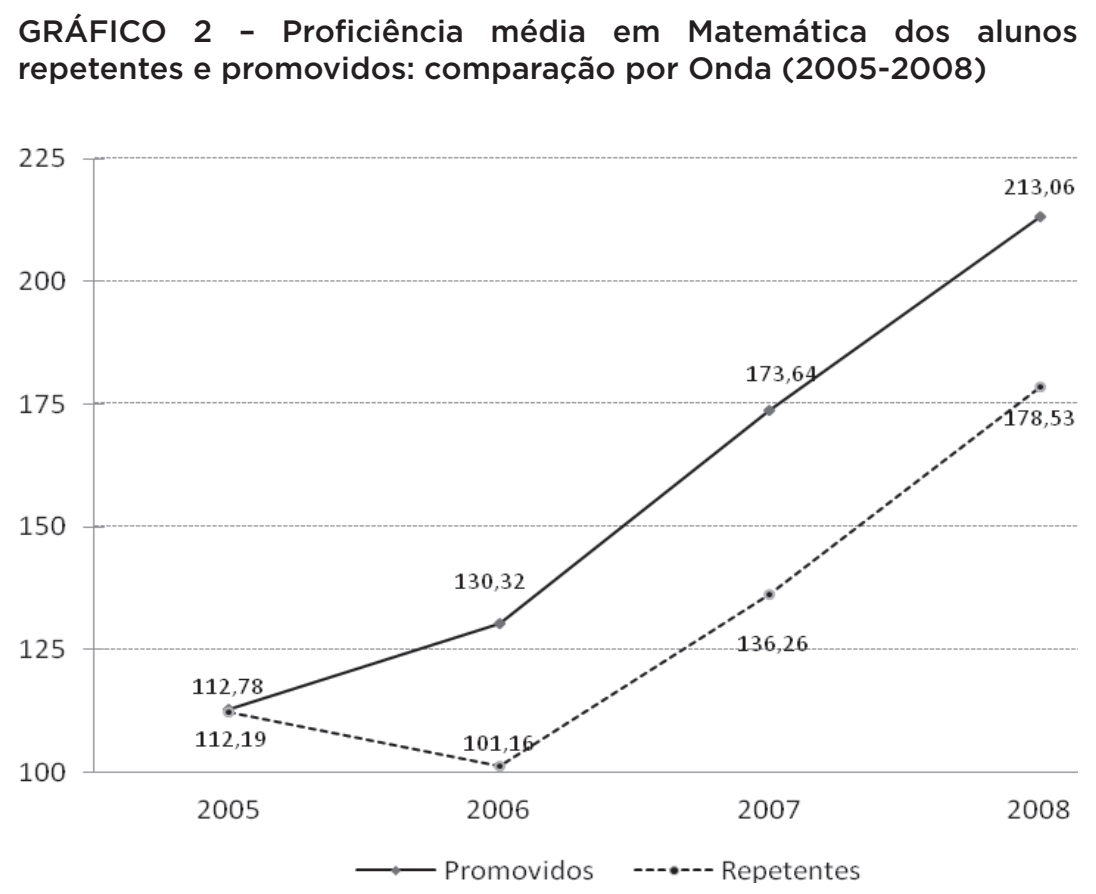

Fonte: Elaboração dos autores.

Ambos os grupos partem de 112 pontos na escala de proficiência em Matemática, na Onda 2. Entretanto, no ano seguinte, promovidos e repetentes apresentam desempenhos muito díspares. Enquanto o grupo de alunos promovidos cresce 17 pontos em 2006, o grupo de repetentes apresenta queda de 11 pontos na escala entre 2005 e 2006 . A partir daí, o crescimento dos dois grupos se acelera significativamente, acumulando 22 pontos entre os repetentes e 33 pontos entre os promovidos ao final de 2008.

Embora os repetentes apresentem, em relação a 2005, uma queda na média da proficiência em Matemática em 2006, a proficiência dos alunos promovidos também apresenta um crescimento menor em 2006 do que nos demais anos. Esse fenômeno já havia sido identificado pelo estudo longitudinal no universo dos alunos participantes e hipóteses sobre essa desaceleração verificada no ritmo de aprendizagem de habilidades de Matemática, entre o $2^{\circ}$ e o $3^{\circ}$ ano escolar, estão sendo analisadas (BROOKE; BONAMINO, 2011). 


\section{COMPARAÇÃO POR SÉRIE (SAME-GRADE COMPARISON)}

Utilizando os mesmos grupos da abordagem anterior, realizamos uma comparação baseada na série (same-grade comparison). Esta abordagem consiste em comparar a proficiência desses dois grupos de alunos a partir da série, independente do ano em que esta série foi cursada. Isso equivale a dizer que, apesar de as medidas serem comparadas a partir de uma mesma série, esses dois grupos de alunos mantém entre si um ano letivo de diferença.

A Figura 3 acompanha o esquema apresentado na seção anterior relativo às ondas de avaliação. A diferença é que as comparações demarcadas pelo pontilhado se dão em um plano horizontal, isto é, em uma abordagem que privilegia a série. Dessa forma, a comparação possibilita destacar qual a diferença entre as proficiências dos alunos repetentes e promovidos em uma mesma série.

FIGURA 3 - Estratégia de comparação por série

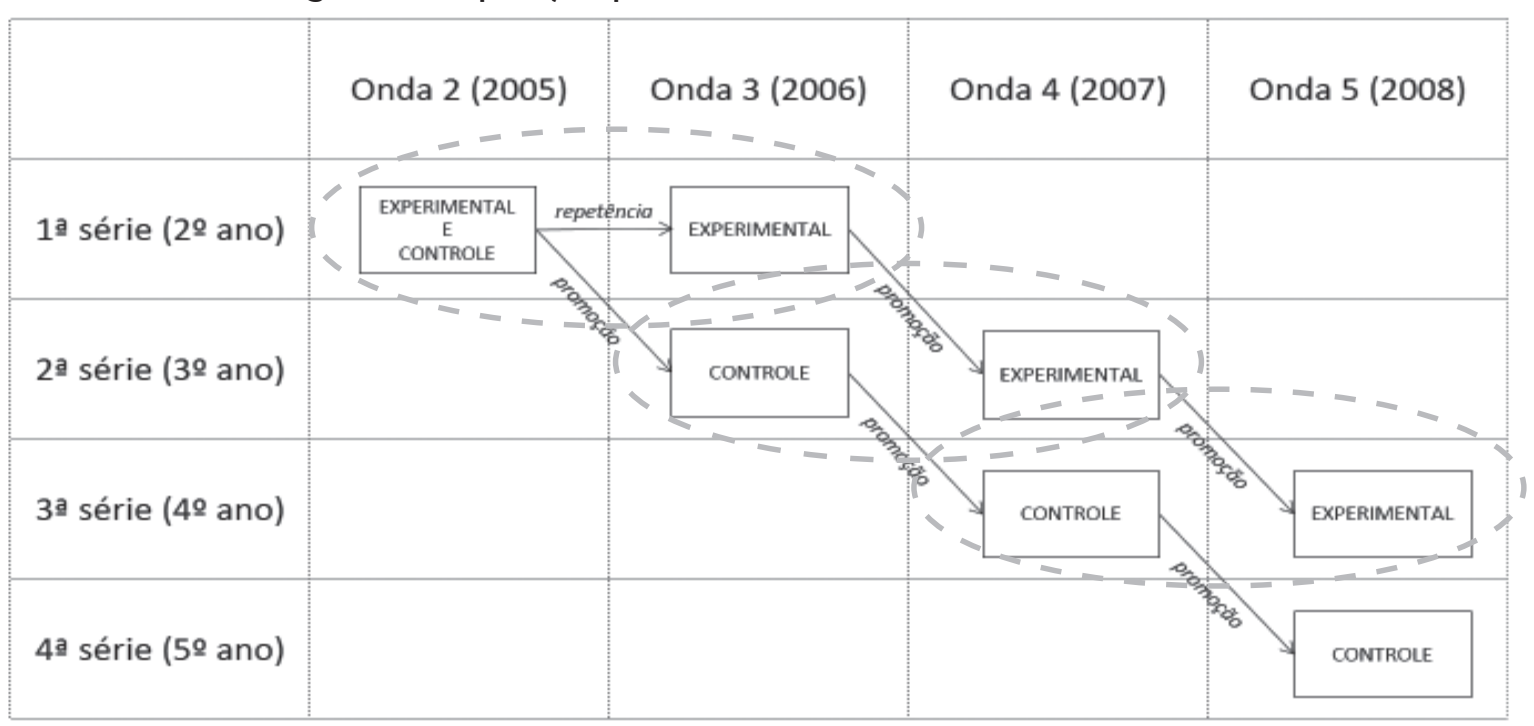

Fonte: Elaboração dos autores.

Os gráficos 3 e 4, a seguir, apresentam a comparação das proficiências de ambos os grupos em Língua Portuguesa e Matemática, respectivamente, ao final da $1^{\mathrm{a}}, 2^{\mathrm{a}}$ e $3^{\mathrm{a}}$ séries. Note-se que o grupo experimental estará sempre cursando as séries em questão com um ano de atraso em relação ao grupo controle. 
GRÁFICO 3 - Proficiência média em Língua Portuguesa dos alunos repetentes e promovidos - comparação por série (2ำ ao $4^{\circ}$ ano/1 à $3^{\text {a }}$ série)

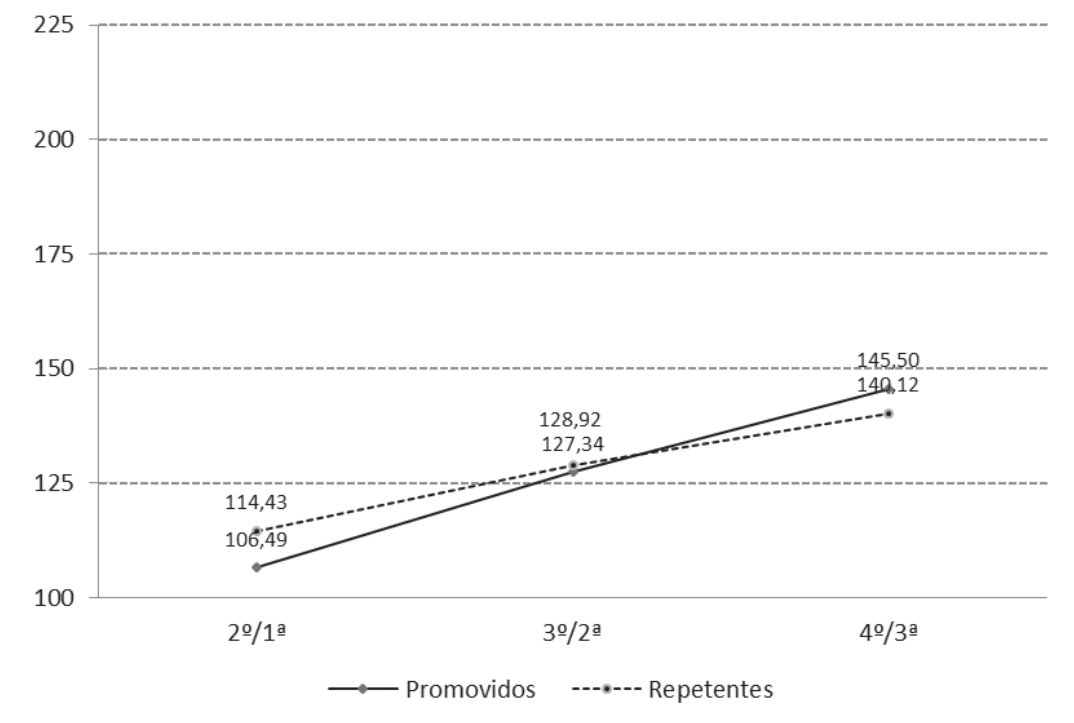

Fonte: Elaboração dos autores.

O Gráfico 3 mostra que, passado um ano após a repetência e ignorando-se o fato de que um ano letivo separa os resultados de ambos os grupos, os alunos repetentes apresentam um resultado mais satisfatório que os promovidos. Entretanto, essa constatação não subsiste a uma observação longitudinal mais extensa. Observa-se que a primeira medida dos alunos repetentes é de 114 pontos. Isso representa a média de proficiência desse grupo no ano de 2006, ou seja, o desempenho desses alunos no estudo longitudinal quando estavam cursando a $1^{\mathrm{a}}$ série $/ 2^{\circ}$ ano pela segunda vez. Nota-se, também, que, após um ano cursando a mesma série, a diferença que esses alunos obtiveram em relação à proficiência de seus pares na mesma série no ano anterior é de apenas 8 pontos. Isso equivale a dizer que ao final de um ano de repetição de um mesmo currículo, a repetência como medida de recuperação das aprendizagens levou à agregação de apenas 8 pontos na média de proficiência em relação não só aos seus pares promovidos, mas também em relação ao próprio grupo, uma vez que as médias destes estavam pareadas no ano anterior. Essa diferença não se mantém no decorrer da 
trajetória escolar. Quando comparados os resultados da $2^{\mathrm{a}}$ série $/ 3^{\circ}$ ano, percebe-se que o suposto "efeito repetência", que já não era grande, reduz-se para apenas 1 ponto, invertendo-se os resultados já na $3^{\mathrm{a}}$ série $/ 4^{\circ}$ ano, quando há uma diferença de 5 pontos, em média, a favor dos não repetentes.

GRÁFICO 4 - Proficiência média em Matemática dos alunos repetentes e promovidos - comparação por série ( $2^{\circ}$ ao $4^{\circ}$ ano $/ 1^{\text {a }}$ à $3^{\text {a }}$ série)

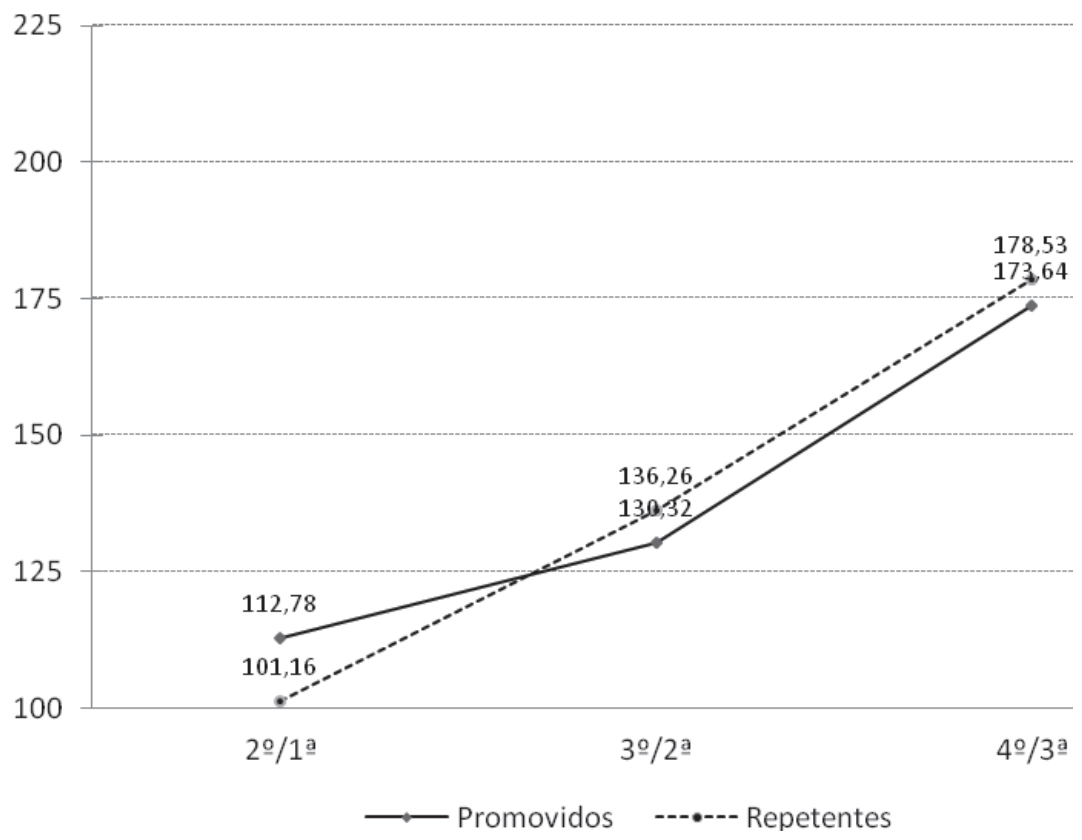

Fonte: Elaboração dos autores.

Matemática apresenta um comportamento diferente quando se comparam as proficiências dos grupos por série. Os alunos repetentes apresentam uma média de 112 pontos na $1^{\mathrm{a}}$ série $/ 2^{\circ}$ ano, que é menor que a dos promovidos em cerca de 8 pontos. Essa diferença a favor dos promovidos na $1^{\mathrm{a}}$ série $/ 2^{\circ}$ ano se deve à queda verificada na proficiência dos alunos repetentes em 2006. A partir da $2^{\mathrm{a}}$ série $/ 3^{\circ}$ ano nota-se uma diferença de 6 pontos a favor dos repetentes. Essa diferença cai cerca de 5 pontos na $3^{\mathrm{a}}$ série $/ 4^{\circ}$ ano.

O período escolar que o estudo longitudinal nos permite acompanhar não é suficiente para saber o que acontece nas séries posteriores à $4^{\mathrm{a}}$ série $/ 5^{\circ}$ ano do ensino fundamental. 
O Quadro 3 apresenta, de forma sintética, as diferenças entre as médias dos repetentes e promovidos, na comparação por onda e por série.

QUADRO 3 - Diferenças entre a média das proficiências dos alunos repetentes e dos promovidos

\begin{tabular}{|c|c|c|c|c|c|c|}
\hline & \multicolumn{3}{|c|}{ COMPARAÇÃO POR ONDA } & \multicolumn{3}{|c|}{ COMPARAÇÃO POR SÉRIE } \\
\hline & 2006 & 2007 & 2008 & $1^{\mathrm{a} / 2^{\circ}}$ & $2^{\mathrm{a}} / 3^{\circ}$ & $3 a / 40$ \\
\hline Português & $-12,9$ & $-16,5$ & $-17,3$ & 7,9 & 1,5 & $-5,3$ \\
\hline Matemática & $-29,1$ & $-37,3$ & $-34,5$ & $-11,6$ & 5,9 & 4,8 \\
\hline
\end{tabular}

Fonte: Elaboração dos autores.

Na comparação por Onda, em 2006, um ano após a decisão de reter o aluno, os repetentes têm, em média, 12 pontos de proficiência a menos em Língua Portuguesa que seus pares promovidos. Em 2007, essa diferença aumenta para aproximadamente 15 pontos, estabilizando-se nesse patamar em 2008. Em Matemática, a diferença entre repetentes e promovidos é mais acentuada, chegando a 29 pontos ao final de 2006, 37 pontos ao final de 2007 e 28 pontos em 2008.

Na comparação por série, ao final de um ano repetido, os alunos repetentes apresentam 8 pontos a mais em Língua Portuguesa em relação aos seus colegas promovidos e ao próprio resultado anterior. Essa diferença se reduz para 3 pontos ao final da $2^{\mathrm{a}}$ série, invertendo-se a favor dos promovidos ao final da $3^{\text {a }}$ serie, em cerca de 3 pontos. Em Matemática, os resultados se apresentam favoráveis à repetência. Alunos repetentes apresentam queda de cerca de 7 pontos na proficiência em relação aos seus pares e a si mesmos ao final da $1^{\mathrm{a}}$ série do ensino fundamental. Há uma inversão dessa tendência na $2^{\mathrm{a}}$ e na $3^{\mathrm{a}}$ séries, que os coloca acima dos promovidos em 13 pontos. Esses resultados estão sintonizados com pesquisas internacionais, que comparam os alunos com base na idade (ou no ano letivo), o que tende a favorecer os alunos promovidos, enquanto as comparações baseadas na mesma série tendem a favorecer os estudantes retidos (HOLMES, 1989). As significâncias estatísticas das diferenças obtidas pelo teste t, para amostras independentes, são apresentadas no Quadro 4. 
QUADRO 4 - Teste de comparação entre as médias dos alunos repetentes e promovidos

\begin{tabular}{|c|c|c|c|c|c|c|c|c|c|}
\hline & & \multicolumn{4}{|c|}{ LÍNGUA PORTUGUESA } & \multicolumn{4}{|c|}{ MATEMÁTICA } \\
\hline & & MÉDIA & $\begin{array}{c}\text { ERRO } \\
\text { PADRÃO }\end{array}$ & ESTAT. $\mathrm{t}$ & $P(T<=t)$ & MÉDIA & $\begin{array}{c}\text { ERRO } \\
\text { PADRÃO }\end{array}$ & ESTAT. $\mathrm{t}$ & $P(T<=t)$ \\
\hline \multirow{2}{*}{$2005(1)$} & Repetentes & 90,85 & 1,71 & \multirow{2}{*}{$-2,89$} & \multirow{2}{*}{0,00} & 89,15 & 2 & \multirow{2}{*}{$-2,84$} & \multirow{2}{*}{0,00} \\
\hline & Promovidos & 97,52 & 1,56 & & & 96,53 & 1,66 & & \\
\hline \multirow{2}{*}{$2005(2)$} & Repetentes & 106,48 & 1,31 & \multirow{2}{*}{$-0,01$} & \multirow{2}{*}{0,50} & 112,19 & 1,88 & \multirow{2}{*}{$-0,22$} & \multirow{2}{*}{0,41} \\
\hline & Promovidos & 106,49 & 1,29 & & & 112,78 & 1,84 & & \\
\hline \multirow{2}{*}{2006} & Repetentes & 114,43 & 1,34 & \multirow{2}{*}{$-6,5$} & \multirow{2}{*}{0,00} & 101,16 & 2,88 & \multirow{2}{*}{$-6,85$} & \multirow{2}{*}{0,00} \\
\hline & Promovidos & 127,34 & 1,47 & & & 130,32 & 3,13 & & \\
\hline \multirow{2}{*}{2007} & Repetentes & 128,92 & 1,42 & \multirow{2}{*}{$-8,08$} & \multirow{2}{*}{0,00} & 136,26 & 3,11 & \multirow{2}{*}{$-8,5$} & \multirow{2}{*}{0,00} \\
\hline & Promovidos & 145,5 & 1,48 & & & 173,64 & 3,11 & & \\
\hline \multirow{2}{*}{2008} & Repetentes & 140,12 & 1,54 & \multirow{2}{*}{$-7,99$} & \multirow{2}{*}{0,00} & 178,53 & 3,76 & \multirow{2}{*}{$-6,45$} & \multirow{2}{*}{0,00} \\
\hline & Promovidos & 157,45 & 1,53 & & & 213,06 & 3,81 & & \\
\hline \multirow{2}{*}{1} & Repetentes & 114,43 & 1,34 & \multirow{2}{*}{4,28} & \multirow{2}{*}{0,00} & 101,16 & 2,88 & \multirow{2}{*}{$-3,4$} & \multirow{2}{*}{0,00} \\
\hline & Promovidos & 106,49 & 1,29 & & & 112,78 & 1,84 & & \\
\hline \multirow{2}{*}{$2^{a} / 3^{-}$} & Repetentes & 128,92 & 1,42 & \multirow{2}{*}{0,77} & 2? & 136,26 & 3,11 & 171 & 809 \\
\hline & Promovidos & 127,34 & 1,47 & & 0,22 & 130,32 & 3,13 & 1,34 & S \\
\hline & Repetentes & 140,12 & 1,54 & & & 178,53 & 3,76 & & \\
\hline - & Promovidos & 145,5 & 1,48 & 2,02 & ו ד, & 173,64 & 3,11 & r & ( \\
\hline
\end{tabular}

Fonte: Elaboração dos autores.

\section{CONCLUSÃO}

Quando um estudante falha em demonstrar as competências necessárias para ser promovido à série seguinte, uma das decisões que cabe ao corpo docente no final do ano é em relação à retenção do aluno na série, sob a justificativa/expectativa de que, no próximo ano, a maturidade e a reexposição aos conteúdos da série irão prepará-lo melhor para as demandas escolares que lhe serão exigidas no decorrer das séries seguintes. Entretanto, esse tipo de decisão docente e os argumentos a favor da retenção na série como intervenção pedagógica para alunos de baixo desempenho acadêmico não têm encontrado respaldo nas evidências empíricas obtidas a partir de uma variedade de metodologias, em mais de meio século de pesquisas sobre o efeito da retenção. Os resultados desses estudos sugerem que reter alunos em uma 
mesma série não acrescenta a eles maiores benefícios em relação aos seus pares promovidos, principalmente nos anos iniciais do ensino fundamental. Pode-se, ainda, baseando-se em outros estudos e outros autores, conjecturar que a repetência pode ter um impacto negativo no desenvolvimento acadêmico, social ou emocional do aluno, com consequências sérias em termos de abandono e evasão escolar.

No trabalho aqui realizado, procurou-se compreender as relações que se estabelecem entre a repetência e o desenvolvimento cognitivo dos alunos repetentes e não repetentes, que foram pareados por meio do pareamento assistido, utilizando-se de variáveis como o NSE e a proficiência prévia em Língua Portuguesa (leitura) e o NSE e a proficiência prévia em Matemática, como controle. A comparação foi realizada por série e por ano letivo ou onda de avaliação.

A comparação do desenvolvimento acadêmico de alunos repetentes e promovidos a partir de uma mesma série mostra que, apesar de ocorrerem ganhos na proficiência em Língua Portuguesa entre os alunos retidos, esses ganhos não se mantêm ao longo do tempo. Em Matemática, embora um pequeno efeito de 5 pontos na escala do Saeb se mantenha até a $4^{\mathrm{a}}$ série $/ 5^{\circ}$ ano, não é suficiente a ponto de colocar esses alunos em níveis de aprendizagem diferentes dos promovidos, de maneira a justificar a repetência. Isso, associado aos resultados da comparação em relação às ondas - que apontam para uma diferença crescente entre promovidos e retidos a favor dos primeiros - permite-nos concluir que, do ponto de vista pedagógico, a repetência não garante a esses alunos melhores condições de aprendizagem que seus colegas promovidos.

Esses resultados se colocam a favor das políticas que visam à superação da retenção nos anos iniciais do ensino fundamental, uma vez que demonstram que reter alunos nesse segmento escolar pode comprometer o aprendizado num momento crucial de desenvolvimento das habilidades de leitura e escrita. Os achados contradizem os discursos que advogam a favor da repetência, mostrando que reter o aluno não é tão vantajoso como se pensa em termos cognitivos, pois não garante vantagens compensatórias futuras aos repe- 
tentes. Mesmo para Matemática, que apresentou resultados mais favoráveis à repetência, essa diferença, embora estatisticamente significativa, não se mostrou relevante em termos pedagógicos, dado que os níveis de habilidades consolidadas não diferem entre promovidos e repetentes para justificar a adoção dessa medida.

\section{REFERÊNCIAS}

BRANDÃO, Zaia; BAETA, Anna Maria Bianchini; ROCHA, Any Dutra Coelho. Evasão e repetência no Brasil: a escola em questão. 2. ed. Rio de Janeiro: Dois Pontos, 1983.

BROOKE, Nigel; BONAMINO, Alícia (Org.). Geres 2005: razões e resultados de uma pesquisa longitudinal sobre a eficácia escolar. Rio de Janeiro: Wallprint, 2011.

CARVALHO, Sandro Sacchet de. Um estudo do impacto das políticas de não retenção sobre o desempenho acadêmico dos alunos nas escolas públicas brasileiras. 2009. Tese (Doutorado) - Pontifícia Universidade Católica do Rio de Janeiro, Rio de Janeiro, 2009.

COOK, Thomas D.; CAMPBELL, Donald Thomas. Quasi-experimentation: design and analysis for field settings. Chicago: Rand McNally, 1979.

CRAHAY, Marcel. É possível tirar conclusões sobre os efeitos da repetência?. Cadernos de Pesquisa, São Paulo, v. 36, n. 127, p. 223-246, jan./abr. 2006.

FLETCHER, Philip. A repetência no ensino de $1^{\circ}$ grau: um problema negligenciado da educação brasileira. Uma análise preliminar e sugestão de avaliação adicional. Revista Brasileira de Administração da Educação, Porto Alegre, v. 3, n.1, p. 10-41, jan./jun. 1985.

FLETCHER, Philip; CASTRO, Cláudio de Moura. Os mitos, as estratégias e as prioridades para o ensino de $1^{\circ}$ grau. Educação e Realidade, Porto Alegre, v. 11, n. 1, p. 35-42, jan./jun. 1986.

FLETCHER, Philip; RIBEIRO, Sérgio da Costa. O ensino de primeiro grau no Brasil de hoje. Em Aberto, Brasília, ano 6, n .33, jan./mar. 1987.

GADOTTI, Moacir; ROMÃO, José Eustáquio Romão. Evolução do ensino fundamental no Brasil: análise das estatísticas e indicadores educacionais. Instituto Paulo Freire, 2000. Disponível em: <http:/|acervo.paulofreire.org/ xmlui/handle/7891/3389>. Acesso em: 07 jan. 2013.

GIL, Natália. Interpretação das estatísticas de educação: um espaço de disputas simbólicas. Revista Brasileira de História da Educação, n. 13, p. 121-151, jan./abr. 2007.

HOLMES, C. Thomas. Grade-level retention effects: a meta-analysis of research studies. In: SHEPARD, L.A.; SMITH, M.L. (Ed.), Flunking grades: research and policies on retention. London, Bristol: The Falmer, 1989. p. 16-33. 
JACKSON, Gregg. The research evidence on the effects of grade retention. Review of Educational Research, v. 45, n. 4, p. 613-636, 1975.

KLEIN, Ruben; RIBEIRO, Sérgio da Costa. O censo educacional e o modelo de fluxo: o problema da repetência. São Paulo: USP/NUPES, nov. 1991.

. A pedagogia da repetência ao longo das décadas. Ensaio: Avaliações e Políticas Públicas em Educação, Rio de Janeiro, v. 3, n. 20, p. 55-61, jul./set. 1998.

LOURENÇO FILHO, Manoel Bergström. A evasão escolar no ensino primário. Revista Brasileira de Estatística, Rio de Janeiro, n. 7, p. 539-552, jul./set. 1941.

Tendências da educação brasileira. 2. ed. Brasília, DF: MEC/Inep, 2002.

LUZ, Luciana Soares. 0 impacto da repetência na proficiência escolar: Uma análise longitudinal do desempenho de repetentes em 2002-2003. 2008. Dissertação (Mestrado) - Universidade Federal de Minas Gerais, Cedeplar, Belo Horizonte, 2008.

MENEZES-FILHO, Naércio et al. Avaliando o impacto da progressão continuada nas taxas de rendimento e desempenho escolar do Brasil. São Paulo: bmec-SP; Fea-USP, 2008. Disponível em: <http://www.sebh.ecn.br/seminario_6/sebh_artigo_ Roberta.pdf>. Acesso em: 27 dez. 2012.

NEVES, Rafael Correia das; PAZELLO, Elaine Toldo. O efeito de políticas de não repetência sobre o desempenho dos estudantes do ensino fundamental. In: ENCONTRO NACIONAL DE ECONOMIA, 40., 2012, Porto de Galinhas. Anais... Porto de Galinhas: Anpec, 2012. Disponível em: < http://www.anpec. org.br/encontro/2012/inscricao/files_I/i11-8f8c89f27396496a52604c0a6e6309 dd.pdf>. Acesso em: 30 jan. 2013.

ORGANIZAÇÃO PARA A COOPERAÇÃO E DESENVOLVIMENTO ECONÔMICO. Quando os estudantes repetem um ano ou são transferidos da escola: o que isso significa para os sistemas de educação?. Pisa em Foco, n. 6, jul. 2011. Disponível em: <http://www.pisa.oecd.org>. Acesso em: 30 dez. 2012.

RIANI, Juliana de Lucena Ruas; SILVA, Vânia Candida da; SOARES, Tufi Machado. Repetir ou progredir? Uma análise nas escolas públicas de Minas Gerais. Belo Horizonte: Cenpec, 2010. Disponível em: < http://www.cenpec. org.br>. Acesso em: 30 jan. 2013.

RIBEIRO, Sérgio da Costa. A pedagogia da repetência. Estudos Avançados, São Paulo, v. 5, n. 12, maio/ago. 1991.

SOARES, Sergei Suarez Dillon. A repetência no contexto internacional: o que dizem os dados de avaliações das quais o Brasil não participa. Brasília: Instituto de Pesquisa Econômica Aplicada, 2007. (Texto para Discussão, n. 1300).

TEIXEIRA DE FREITAS, Mario Augusto. O que dizem os números sobre o ensino primário. In: LOURENÇO FILHO, Manuel Bergströn (Org.). Bibliotheca da Educação. v. 27. São Paulo: Melhoramentos, 1937.

. Ainda a evasão escolar no ensino primário brasileiro. Revista Brasileira de estatística, Rio de Janeiro, v. 2, n. 7, p. 553-642, jul./set. 1941. 


\section{ERISSON VIANA CORREA}

Doutorando do Programa de Pós-Graduação em Educação da Pontifícia Universidade Católica do Rio de Janeiro (PUC-Rio). Integrante do Laboratório de Avaliação da Educação (LAEd) da Puc-Rio. Orientador Pedagógico do Colégio Pedro II, Rio de Janeiro, Rio de Janeiro, Brasil erisson@cp2.g12.br

\section{ALICIA BONAMINO}

Professora Doutora do Departamento de Educação da Pontifícia Universidade Católica do Rio de Janeiro (PUC-Rio). Coordenadora do Laboratório de Avaliação da Educação (LAEd) da PUC-Rio, Rio de Janeiro, Rio de Janeiro, Brasil alicia@puc-rio.br

\section{TUFI MACHADO SOARES}

Professor Doutor do Departamento de Estatística e do Programa de Pós-Graduação em Educação da Universidade Federal de Juiz de Fora (UFJF). Coordenador de Pesquisa do Centro de Políticas Públicas e Avaliação da Educação (CAEd) da UFJF, Juiz de Fora, Minas Gerais, Brasil tufi@caed.uff.br 